\title{
Mitigation of acute radiation-induced brain injury in a mouse model using anlotinib
}

\author{
Xiao-Han Gao ${ }^{1}$, Jing Zheng ${ }^{2}$, Long $\mathrm{Ma}^{3}$, Long-Bo Ma ${ }^{1}$, Yu-Jie Zhai ${ }^{1}$, Fang-Fang Yang ${ }^{4}$, Sheng-Jie Wang ${ }^{5}$, \\ Qing-Shuai Fan ${ }^{1}$, Jie Wen ${ }^{6}$, Heng-Lu Wang ${ }^{7}$, Xiao-Han Wu ${ }^{1}$, Shao-Shui Chen ${ }^{1}$, Chang-Min Liu ${ }^{1}$ \\ ${ }^{1}$ Department of Oncology, Binzhou Medical University Hospital, Binzhou, China; ${ }^{2}$ Department of Science and Technology, Binzhou Medical \\ University Hospital, Binzhou China; ${ }^{3}$ Department of Radiotherapy, Shanxi Provincial People's Hospital, Taiyuan, China; ${ }^{4}$ Qingdao University, \\ Qingdao, China; ${ }^{5}$ Department of Oncology, Yantai Affiliated Hospital of Binzhou Medical University, Yantai, China; ${ }^{6}$ Department of Oncology, \\ People's Hospital of Qingdao West Coast Area, Qingdao, China; ${ }^{7}$ Department of Vascular Interventional, Binzhou Medical University Hospital, \\ Binzhou, China \\ Contributions: (I) Conception and design: SS Chen, CM Liu, J Zheng, XH Gao, L Ma; (II) Administrative support: LB Ma, YJ Zhai, FF Yang; \\ (III) Provision of study materials or patients: SJ Wang, QS Fan; (IV) Collection and assembly of data: J Wen, XH Wu; (V) Data analysis and \\ interpretation: XH Gao, L Ma, HL Wang; (VI) Manuscript writing: All authors; (VII) Final approval of manuscript: All authors. \\ Correspondence to: Shao-Shui Chen; Chang-Min Liu. Department of Oncology, Binzhou Medical University Hospital, No. 661, The Second Huanghe \\ Road, Binzhou, China. Email: byfychenss@126.com; byfylcm@126.com.
}

Background: With the development of radiological technologies, radiotherapy has been gradually widely used in the clinic to intracranial tumours and become standardised. However, the related central nervous system disorders are still the most obvious complications after radiotherapy. This study aims to quantify the effectiveness of anlotinib, a small molecule inhibitor of multiple receptor tyrosine kinases, in mitigating acute phase of radiation-induced brain injury (RBI) in a mouse model.

Methods: The onset and progression of RBI were investigated in vivo. All mice, (except for the sham group) were irradiated at a single-fraction of 20 Gy and treated with different doses of anlotinib (0, 0.2 and $0.8 \mathrm{mg} / \mathrm{kg}$, respectively). The expression levels of glial fibrillary acidic protein (GFAP), hypoxia-inducible factor-1 $\alpha$ (HIF-1 $\alpha$ ), vascular endothelial growth factor (VEGF), and phosphorylated vascular endothelial growth factor receptor-2 (p-VEGFR2) were assessed by western blot. Histological changes were identified by luxol fast blue (LFB) staining.

Results: The expression levels of GFAP, HIF-1 $\alpha$, and VEGF were downregulated following treatment with anlotinib. However, anlotinib failed to inhibit the development of demyelination. Cerebral edema [as measured by brain water content (BWC)] was also mitigated following treatment with anlotinib.

Conclusions: In summary, treatment with anlotinib significantly mitigated the adverse effects of acute RBI in a dose-dependent manner by downregulating the activation of astrocytes, improving brain hypoxia, and alleviating cerebral edema.

Koywords: Anlotinib; glial fibrillary acidic protein (GFAP); HIF-1 $\alpha$; vascular endothelial growth factor (VEGF); radiotherapy

Submitted Oct 16, 2020. Accepted for publication Jan 02, 2021.

doi: 10.21037/apm-20-2284

View this article at: http://dx.doi.org/10.21037/apm-20-2284 


\section{Introduction}

At present, radiotherapy is one of the most common forms of treatment for various malignant tumours of the central nervous system (CNS). Previous studies have demonstrated that, despite its effectiveness in reducing tumour growth, radiation can induce significant brain injury after treatment (1). Radiation-induced brain injury (RBI) can be divided into three phases: acute (within 2 weeks following the initiation of radiotherapy), early-delayed (2-6 months after radiotherapy), and late-delayed (several months up to a few years after radiotherapy) $(1,2)$. Yet, despite enormous efforts, the exact pathophysiological mechanism of RBI remains elusive. Parenchymal damage (1), vasogenic damage (3-5), autoimmune response (6), astrocytic response (7), and free radical damage (8) have been widely asserted Previous research on RBI referring to the vasculature, glial cells, and hypoxia (or a combination of these), have already benefited from rodent models with single or fractionated radiation dose schedules (9-11).

Deng et al. (8) investigated X-ray results in timedependent activation of astrocytes in irradiated mice brains. Astrocyte could be specifically labeled by glial fibrillary acidic protein (GFAP) $(12,13)$. It is well established that activated astrocytes participate in RBI through the secretion of cytokines such as vascular endothelial growth factor (VEGF) and hypoxia-inducible factor-1 (HIF-1) (14). Transmission of essential signals under associated hypoxia after irradiation is mediated by HIF-1 (11), which is composed of the basic proteins HIF-1 $\beta$ and HIF-1 $\alpha$, and is rapidly degraded under normoxia $(15,16)$. Under normal physiological conditions, VEGF is capable of regulating angiogenic processes and exerts biological effects mainly by integrating with vascular endothelial growth factor receptor-2 (VEGFR2) (17-20). Contrary to the conventional wisdom, the overexpression of VEGF is correlated with high-level permeability across the endothelial barrier and accelerates vascular dysfunction of the blood-brain barrier (BBB), resulting in associated cerebral edema, further prompting the occurrence and development of RBI (21).

Previous studies have already confirmed the effectiveness of the application of bevacizumab (Roche, Basel, Switzerland), an anti-VEGF antibody, alone or in combination with other agents, in relieving the associated complications of radiotherapy (22-25). Therefore, it remains possible that similar therapeutic effects could also be achieved with VEGF receptor inhibitors. However, to our knowledge, researchers have only rarely examined the therapeutic effects of using an anti-VEGFR antibody (such as anlotinib) on RBI. Anlotinib is a small molecule inhibitor of multiple receptor tyrosine kinases, and exerts high selectivity for VEGFR2 (26). It is clinically significant in the treatment of many malignant tumours, and works by inhibiting the VEGF cascade signaling pathway and blocking the phosphorylation of VEGFR2 $(27,28)$. Clinical phase III trials of anlotinib have been completed in China $(29,30)$, and clinical phase II or III trials for various sarcomas and carcinomas are ongoing (26).

In this study, we established an RBI model in mice (irradiated with a single-fraction of $20 \mathrm{~Gy}$ ), which could be confirmed via detection of the S100 calcium-binding protein B (S100B). Additionally, we evaluated the changes in demyelination, neuroglia activation, hypoxia, and microvascular permeability following treatment with anlotinib. We present the following article in accordance with the ARRIVE reporting checklist (available at http:// dx.doi.org/10.21037/apm-20-2284).

\section{Methods}

\section{Animals and ethical approval}

In total, 50 mice [C57 black 6 (C57BL/6), male, aged 6-8 weeks, weight $20 \pm 5 \mathrm{~g}$ at the time of irradiation] were purchased from Jinan Pengyue Bioscience Co., Ltd. (Jinan, Shandong, China). The animals were housed three to five per cage, in a pathogen-free environment $\left(22 \pm 3{ }^{\circ} \mathrm{C}\right.$, $45-55 \%$ humidity, and a 12-h light-dark cycle), ad libitum to water and food until the experiment was conducted. All experimental procedures were conducted in accordance with the National Research Council Guide for the Care and Use of Laboratory Animals and were approved by the Ethics Committee of Binzhou Medical University (No. 20191101-11).

\section{Whole-brain irradiation and experimental design}

The RBI mouse model was successfully achieved in the pre-experiments via whole-brain irradiation with a singlefraction of $20 \mathrm{~Gy}$ ( $50 \%$ isodose). Mice were randomized into four groups, with 10 mice in each group: (I) sham group; (II) irradiation group (IR group); (III) irradiation + anlotinib low dose treatment group (AL group); (IV) irradiation + anlotinib high dose treatment group ( $\mathrm{AH}$ group). All of the mice were anesthetized by intraperitoneal injection with $1 \%$ pentobarbital $(50 \mathrm{mg} / \mathrm{kg})$ prior to the 
initiation of radiation. The mice in the $\mathrm{IR}, \mathrm{AL}$, and $\mathrm{AH}$ groups were restrained in the sternal recumbent position on a treatment table and underwent whole-brain irradiation with $20 \mathrm{~Gy}, 6 \mathrm{mv} \mathrm{X}$-ray delivered by a linear accelerator (Varian, Palo Alto, CA, USA).

Anlotinib stock solution (Chia Tai Tianqing, Nanjing, Jiangsu, China) was prepared in saline. Mice in the AL and $\mathrm{AH}$ groups were then treated with the prepared anlotinibsaline stock solution $(0.2 \mathrm{mg} / \mathrm{kg}, 0.8 \mathrm{mg} / \mathrm{kg}$, respectively); oral administration, once daily for 14 successive days. Brain tissue sampling was conducted at 3, 7, and 14 days after the initiation of irradiation. For histological examination, the mice were anesthetized with pentobarbital, then intracardially perfused with heparinized saline until the colorless fluid was obtained. Brain tissue was dissected and subsequently submerged in $10 \%$ neutral formalin for $24 \mathrm{~h}$ at $4^{\circ} \mathrm{C}$. The tissue was then dehydrated, embedded in paraffin, and $4 \mu \mathrm{m}$ sections were taken. For western blot and enzyme-linked immunosorbent assay (ELISA), anesthetized mice were killed by cervical dislocation, and brain tissue was stored at $-80^{\circ} \mathrm{C}$ until processing.

\section{Enzyme-linked immunosorbent assay (ELISA)}

S100B expression was determined using an ELISA Kit (Abcam, Cambridge, UK). The samples were weighed and then minced into small pieces, and subsequently homogenized in chilled $1 \times$ cell extraction buffer $(1 \mathrm{~mL}$ is appropriate for $100 \mathrm{mg}$ tissue pieces) with a glass homogenizer. They were then incubated on ice for 20 minutes. Next, the supernatant were obtained after centrifugation for 20 minutes at $18,000 \times$ g. $50 \mu \mathrm{L}$ supernatant of sample (diluted 10 times) was added to the appropriate wells. Next, $50 \mu \mathrm{L}$ of antibody cocktail was added to each well in the same measure, and incubated for 60 minutes at room temperature on a plate shaker set to $400 \mathrm{rpm}$, covered with an adhesive strip. Immediately following this, each well was washed with $1 \times$ wash buffer three times and incubated with $100 \mu \mathrm{L}$ of tetramethyl benzidine (TMB) development solution for 5 minutes, protected from light. Finally, termination was achieved with the addition of stop solution, and the absorbance was measured at $450 \mathrm{~nm}$ using a microtiter plate reader within 15 minutes.

\section{Determination of brain water content (BWC)}

BWC was measured using the wet/dry (W/D) weight method to quantify the degree of cerebral edema. After dissection, the brain tissue was immediately weighed in order to obtain the wet weight (WW) using an electronic analytical balance. Obtaining the dry weight (DW) involves the placement of brain tissue in an oven at $110^{\circ} \mathrm{C}$, for 12 hours, which is subsequently weighed again using the same method. The actual BWC was estimated using the following formula: $\mathrm{BWC}(\%)=(\mathrm{WW}-\mathrm{DW}) / \mathrm{WW} \times 100 \%$.

\section{Luxol fast blue (LFB) staining}

For histological studies, all staining methods were performed on formalin-fixed, paraffin-embedded sections. Three sections were counted per animal for a minimum of three animals in each group. Tissue sections were immersed into preheated LFB dye solution at $65^{\circ} \mathrm{C}$ for 4 hours. Subsequently, tap water was used for rinsing, and all sections were cooled to ambient temperature. Sections were then treated with lithium carbonate differentiation liquid for 2 seconds, followed by gradient alcohol and xylene dehydration.

\section{Western blot}

To confirm the changes in GFAP, HIF- $1 \alpha$, VEGF, and phosphorylated vascular endothelial growth factor receptor-2 (p-VEGFR2), we performed western blotting. The brain samples were weighed and placed into a homogenizer to be ground into tissue homogenate. For protein extraction, the tissue was homogenized with 10 volumes of ice-cold radio-immunoprecipitation assay (RIPA) buffer (Beyotime, Shanghai, China) containing protease inhibitors. The supernatant was collected after centrifugation at $4{ }^{\circ} \mathrm{C}$ for 20 minutes at $13,000 \times \mathrm{g}$, and the total protein concentration was detected using a bicinchoninic acid (BCA) kit (Beyotime, Shanghai, China). Equal amounts of protein from each fraction were separated by $10 \%$ sodium dodecyl sulfate polyacrylamide gel electrophoresis (SDS-PAGE) for 30 minutes at $80 \mathrm{~V}$, followed by 100 minutes at $120 \mathrm{~V}$, and then transferred to the polyvinylidene fluoride PVDF membrane (Biosharp, Hefei, Anhui, China) for 120 minutes in a transfer buffer. Non-specific binding sites were blocked by $7 \%$ skim milk for 120 minutes, and the membrane was incubated overnight with specific antibodies at $4{ }^{\circ} \mathrm{C}$ for 12 hours. Rabbit anti-GFAP (Abcam, Cambridge, UK), Rabbit antiHIF-1 $\alpha$ (Bosterbio, Pleasanton, CA, USA), Rabbit anti-pVEGFR2 (Abcam, Cambridge, UK), and Rabbit anti- $\beta$ actin (Huabio, Hangzhou, Zhejiang, China) were used. The 
membranes were washed three times for 10 minutes with the mixture of tris-buffered saline and tween 20 (TBST) and then incubated for 60 minutes with Goat anti-Rabbit antibody (Huabio, Hangzhou, Zhejiang, China) at room temperature. The immunoblots were evaluated by efficient chemiluminescence plus (ECL-plus) reagent (Beyotime, Shanghai, China).

\section{Statistical analysis}

All of the data were expressed as mean \pm standard deviation (SD) using SPSS 17.0 software (SPSS, Chicago, IL, USA). One-way analysis of variance (ANOVA) was employed to analyze differences among the groups at different time points, followed by the Tukey multi-comparison test. ${ }^{*} \mathrm{P}<0.05$ or ${ }^{* *} \mathrm{P}<0.01$ were considered statistically significant.

\section{Results}

\section{Upregulation of S100B after irradiation}

At 1 day after irradiation, the expression of S100B in the brains of the mice was detected using ELISA to confirm

Table 1 Significant upregulation of S100 calcium-binding protein B (S100B) after irradiation in the pre-experiment

\begin{tabular}{lcc}
\hline Groups & $\begin{array}{c}\text { Concentration of S100B }(\mathrm{ng} / \mathrm{mg}) \\
(\text { mean } \pm \mathrm{SD})\end{array}$ & $\mathrm{N}$ \\
\hline Sham group & $14.51 \pm 1.05$ & 3 \\
IR group & $40.93 \pm 0.64^{\mathrm{a}}$ & 3 \\
\hline a , compared to the sham group, a significant increase in $\mathrm{S} 100$ \\
$\begin{array}{l}\text { calcium-binding protein B }(\mathrm{S} 100 \mathrm{~B}) \text { was detected in the irradiation } \\
\text { group (IR group) }(\mathrm{P}<0.01) .\end{array}$
\end{tabular}

the construction of the RBI model in the pre-experiment. As shown in Table 1, the expression level of S100B in the IR group was significantly increased compared to the sham group $\left({ }^{* *} \mathrm{P}<0.01\right)$.

\section{Anlotinib alleviated cerebral edema after irradiation}

We quantified the degree of irradiation-associated cerebral edema by measuring the BWC (Table 2). Compared to the sham group, whole-brain irradiation induced a significant increase in BWC in the IR group at any time point $\left({ }^{*} \mathrm{P}<0.05\right.$ at 3 and 7 days; ${ }^{* *} \mathrm{P}<0.01$ at 14 days). Furthermore, BWC was significantly lower in both Anlotinib treated groups during the entire observation period compared to the IR group $\left({ }^{*} \mathrm{P}<0.05\right)$. However, only a slight difference was observed between the AL and AH group at 3 and 7 days $\left({ }^{*} \mathrm{P}<0.05\right)$, while a significant difference was detected at 14 days $\left({ }^{*} \mathrm{P}<0.05\right)$. This phenomenon indicates the involvement of anlotinib in reducing irradiation-induced cerebral edema. Moreover, we observed a gradually increase in the BWC from 3 to 7 days, and a sharp increase from 7 to 14 days in all groups except for the sham group.

\section{Pathological changes in myelin sheath structure}

We also performed LFB staining for myelin sheath of irradiated mice brain at 3, 7, and 14 days to investigate whether anlotinib has a role in preventing demyelination after irradiation. The normal structure of the myelin sheath was observed in the sham group, with no significant demyelination (Figure 1). In the IR group, significant disruption was initially observed at 3 days, characterized by ruptured myelin, and became more prominent as time progressed. However, there was no apparent reduction of demyelination in both the $\mathrm{AL}$

Table 2 Anlotinib alleviated the development of brain water content (BWC) in a dose-dependent manner

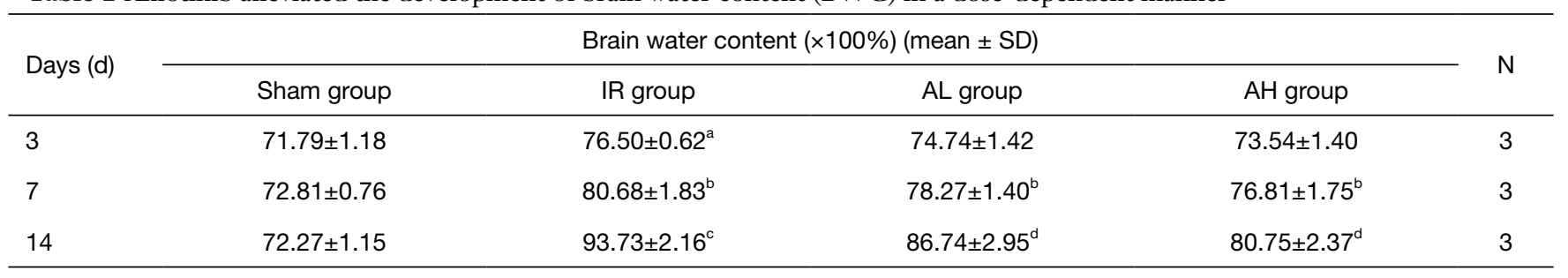

${ }^{\text {a }}$, compared to the sham group, a significant increase in brain water content was detected in irradiation group (IR group) at day $3(P<0.05)$;

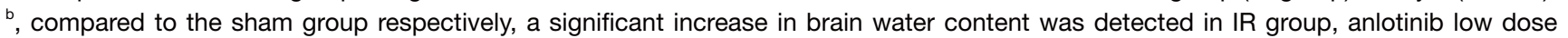
treatment group (AL group) and anlotinib high dose treatment group (AH group) at day 7 ( $\mathrm{P}<0.05)$; ${ }^{\circ}$, compared to the sham group, a significant increase in brain water content was detected in IR group at day $14(\mathrm{P}<0.01) ;{ }^{d}$, there was a significant difference between the $\mathrm{AL}$ group and the $\mathrm{AH}$ group, with lower brain water content detected in the $\mathrm{AH}$ group at 14 days after irradiation $(\mathrm{P}<0.05)$. 

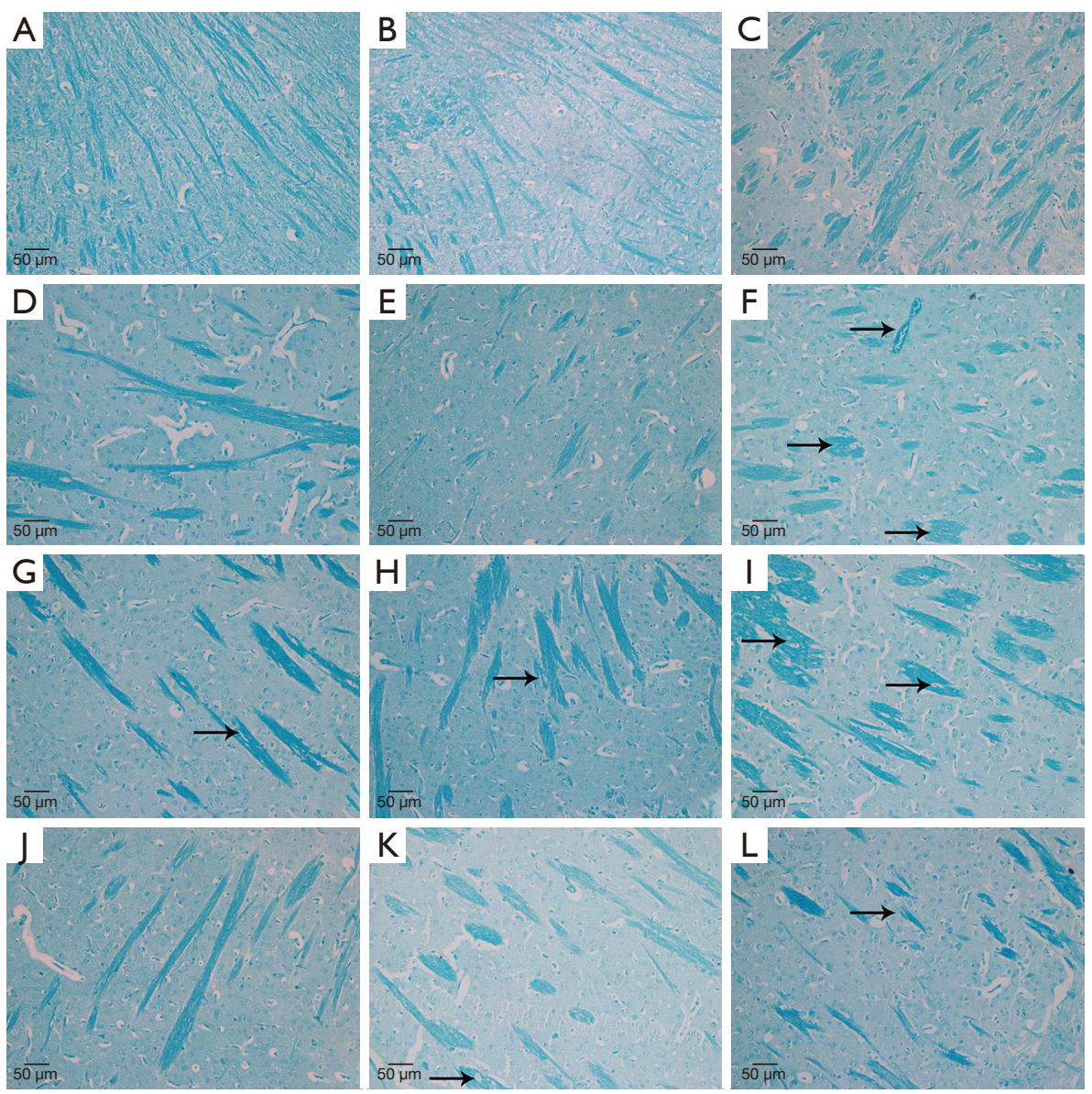

Figure 1 Disruption of the myelin sheath structure (by using LFB staining). (n=3, original magnifications $\times 200)$. (A,B,C) Normal myelin sheath structure of the sham group; (D,E,F) ruptured myelin of the irradiation group (IR group) at 3, 7, and 14 days after irradiation (examples indicated by arrows); (G,H,I) ruptured myelin of the anlotinib low dose treatment group (AL group) at 3, 7, and 14 days after irradiation (examples indicated by arrows); (J,K,L) ruptured myelin of the anlotinib high dose treatment group (AH group) at 3, 7, and 14 days after irradiation (examples indicated by arrows).

and $\mathrm{AH}$ groups compared to the IR group.

\section{Treatment with anlotinib downregulated the expression of GFAP and HIF-1a}

To further explore RBI, we performed western blotting to investigate the expression and relationship between GFAP and HIF- $1 \alpha$ in the mice sacrificed at 3, 7, and 14 days after irradiation. As shown in Figure $2 A$, the expression of GFAP in the IR group was the highest among the four groups $\left({ }^{*} \mathrm{P}<0.05\right.$, respectively). In the IR group, there was an apparent elevation in GFAP expression from 3 to 7 days after irradiation, followed by a lower level at 14 days $\left({ }^{*} \mathrm{P}<0.05\right)$. As for the anlotinib treatment groups, the reduction in the expression of GFAP was more significant in the $\mathrm{AH}$ group compared to the $\mathrm{AL}$ group $\left({ }^{*} \mathrm{P}<0.05\right)$.

We also examined the irradiation-induced protein expression of HIF-1 $\alpha$, a responsive-gene of hypoxia. Similar to the results of GFAP, the expression of HIF-1 $\alpha$ was significantly increased as early as 3 days after irradiation, reaching a peak at 7 days, followed by a reduction at 14 days (except in the sham group). As shown in Figure 2B, the expression of HIF- $1 \alpha$ in the IR group was significantly upregulated after irradiation relative to the sham group $\left({ }^{*} \mathrm{P}<0.05\right)$, and was significantly decreased in the AL group compared with the IR group $\left({ }^{*} \mathrm{P}<0.05\right)$. Moreover, at 14 days after irradiation, the AH group exhibited a noticeably greater decrease in the expression of HIF- $1 \alpha$ 
A

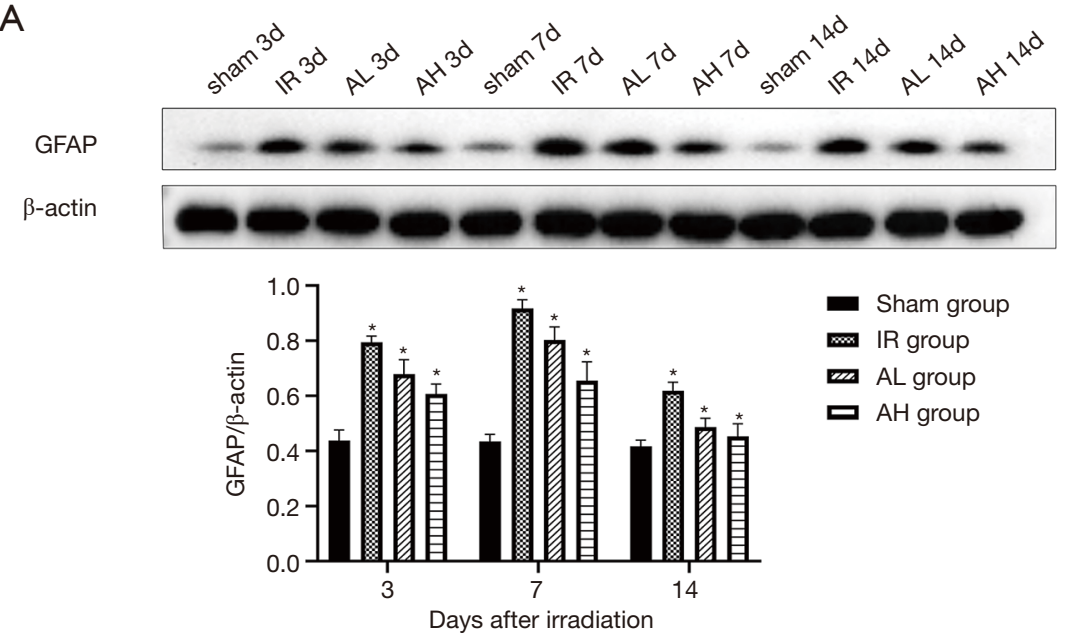

B

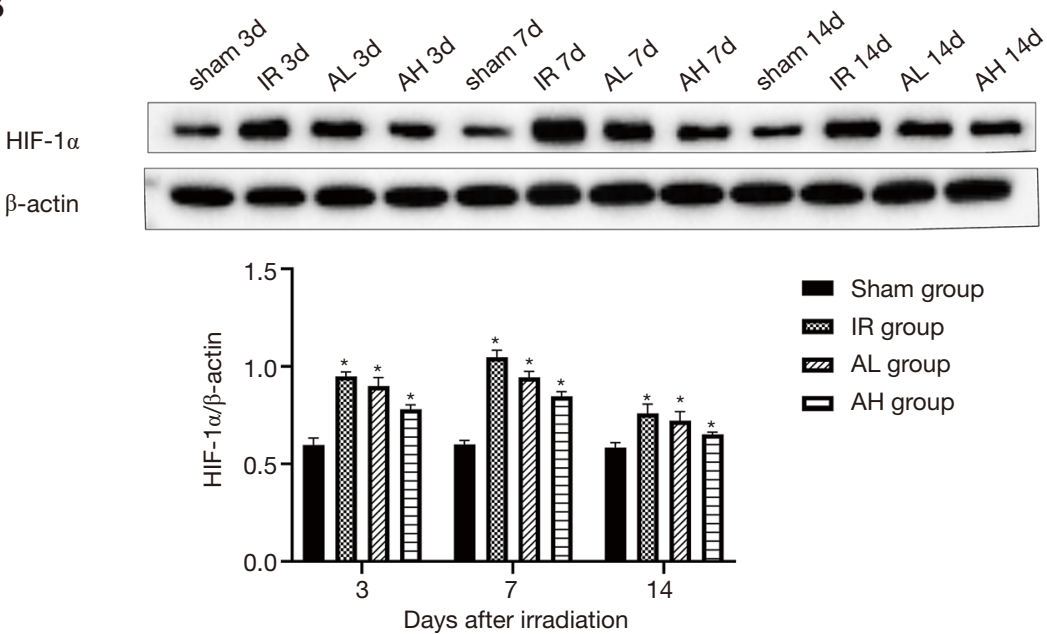

Figure 2 Effects of whole-brain irradiation on protein expression of glial fibrillary acidic protein (GFAP) and hypoxia-inducible factor-1 $\alpha$ $(\mathrm{HIF}-1 \alpha)$ in the brains of mice. Quantitative analysis of GFAP and HIF-1 $\alpha$ was carried out using the Tukey multi-comparison test ( $\mathrm{n}=3$, mean \pm SD). (A) Expression of GFAP at 3, 7, and 14 days after irradiation; (B) expression of HIF-1 $\alpha$ at 3, 7, and 14 days after irradiation. *, $\mathrm{P}<0.05$ compared to the sham group; the irradiation group (IR group) vs. the anlotinib low dose treatment group (AL group), * $\mathrm{P}<0.05$; the AL group $v s$. the anlotinib high dose treatment group (AH group), ${ }^{*} \mathrm{P}<0.05$.

than both the IR $\left({ }^{*} \mathrm{P}<0.05\right)$ and the AL group $\left({ }^{*} \mathrm{P}<0.05\right)$, yet was still higher than the sham group $\left({ }^{*} \mathrm{P}<0.05\right)$.

\section{Anlotinib upregulated the expression of VEGF by over- inbibiting the phosphorylation of VEGFR2}

Given the critical role of the VEGF/VEGFR2 signaling cascade in the RBI model, we further evaluated the expression in p-VEGFR2 (Figure $3 A$ ) and the level of VEGF (Figure $3 B$ ) by western blot. The IR group exhibited increased levels of p-VEGFR2 at 3, 7, and 14 days after irradiation; markedly higher than those in the sham group $\left({ }^{*} \mathrm{P}<0.05\right)$. Moreover, the level of $\mathrm{p}-\mathrm{VEGFR} 2$ increased progressively over time, and was correlated with the upregulation of VEGF, suggesting involvement of the VEGF/VEGFR pathway in the acute early phase of RBI. Contrary to the results in the IR group, treatment with anlotinib was associated with a significant reduction in the level of p-VEGFR2 up to 14 days after irradiation $\left({ }^{*} \mathrm{P}<0.05\right)$. It could be seen that in the IR group, the expression of VEGF peaked at 7 days after irradiation, while both the $\mathrm{AL}$ and $\mathrm{AH}$ group remained at increasing levels at this time point, and reached a peak at 14 days. Quantitative differences existed in the expression of VEGF following 

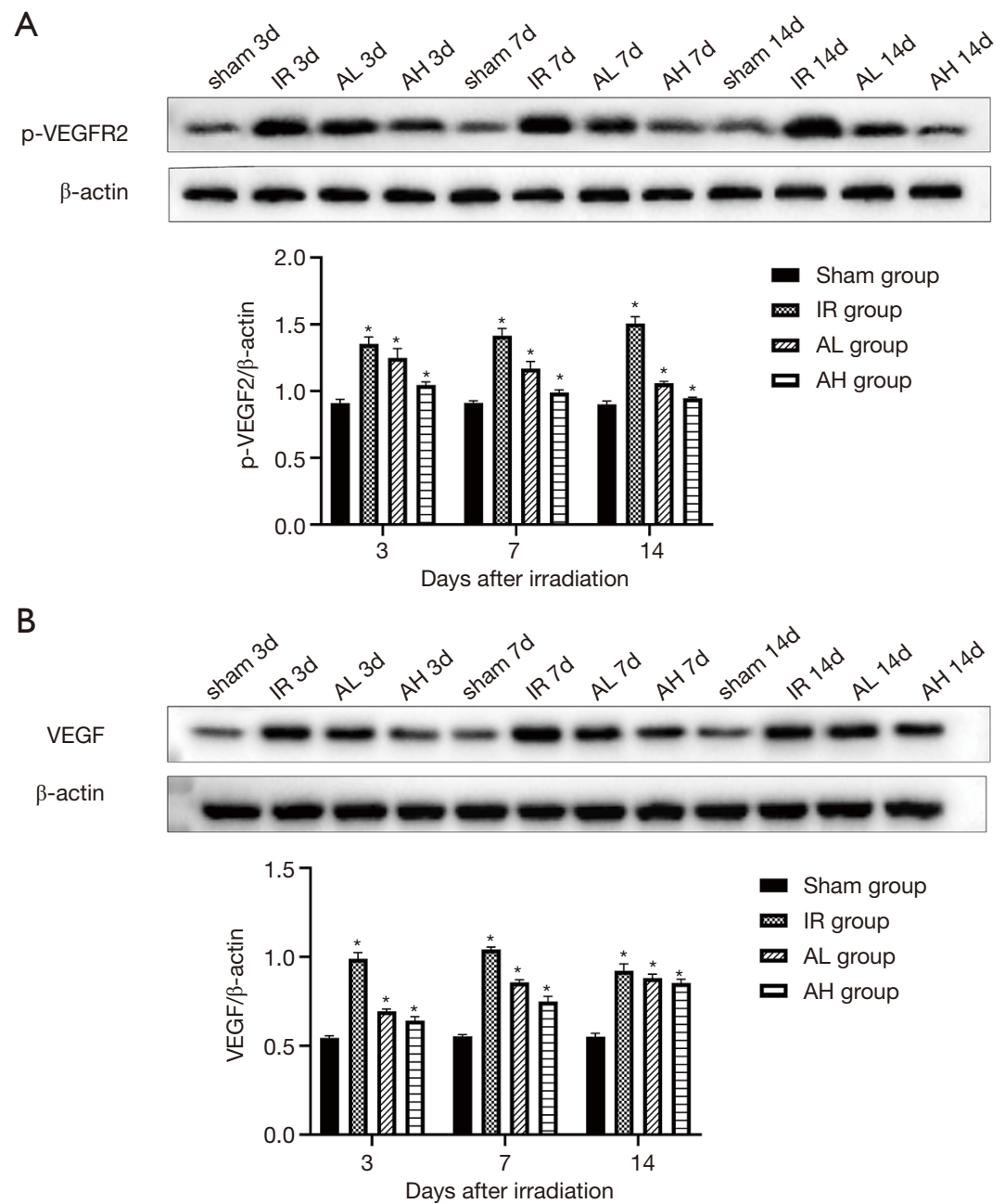

Figure 3 Effects of whole-brain irradiation on protein expression of phosphorylated vascular endothelial growth factor receptor-2 (p-VEGFR2) and vascular endothelial growth factor (VEGF) in the brains of mice. Quantitative analysis of p-VEGFR2 and VEGF was carried out using the Tukey multi-comparison test ( $=3$, mean \pm SD). (A) Expression of p-VEGFR2 at 3, 7, and 14 days after irradiation; (B) expression of VEGF at 3, 7, and 14 days after irradiation. * $\mathrm{P}<0.05$ compared to the sham group; the irradiation group (IR group) vs. the anlotinib low dose treatment group (AL group), ${ }^{*} \mathrm{P}<0.05$; the $\mathrm{AL}$ group $v$ s. the anlotinib high dose treatment group $\left(\mathrm{AH}\right.$ group), ${ }^{*} \mathrm{P}<0.05$.

treatment with different doses of anlotinib, implying a higher level for the AL group at any time point $\left({ }^{*} \mathrm{P}<0.05\right)$.

\section{Discussion}

At present, radiotherapy is used widely in the treatment of malignant tumours in the CNS, as the radiotherapeutic fields inevitably involve irradiation of the focal normal brain, which can result in major adverse effects (such as RBI) (31). Previous studies have reported that neuronal necrosis, demyelination, neuroglia activation, hypoxia, and disruption of the BBB are prominent features of acute-phase RBI, occurring within two weeks after irradiation $(1,2,11,32,33)$. Clinically, these changes may be responsible for a series of complications, such as progressive neurocognitive deficits, hemodynamic disorders, and cerebral edema-induced elevated intracranial pressure $(34,35)$. Due to the inevitable complications, efforts have been under taken to elucidate the pathogenic mechanisms of radiation-associated injury. Accordingly, rodent models irradiated with $\mathrm{X}$-ray present a unique opportunity to explore the pathogenesis of RBI, and have achieved early success in the development of efficacious therapies (2). Bevacizumab is a specific antiVEGF antibody that has been shown to be effective in 
inhibiting the progress of RBI; thus a similar therapeutic effect remains possible with the anti-VEGFR antibody, anlotinib.

In the present study, we investigated the pathology of acute RBI over time by establishing an RBI model in mice, which was evaluated by western blotting and ELISA, and compared to those with anlotinib treatment after irradiation. To determine whether the brain injury model was successfully constructed, the expression level of S100B was detected in the pre-experiment. Donato (36) asserted that $\mathrm{S} 100 \mathrm{~B}$ is mostly secreted by mature astrocytes and is identified with little expression under normal physiological conditions. Furthermore, since it is not expressed extracranial tissue, $\mathrm{S} 100 \mathrm{~B}$ is a promising potential marker for the diagnosis of various CNS disorders, including ischemic, traumatic, and degenerative injuries (37-40). In our study, we observed significant overexpression of S100B in irradiated mice brain. Therefore, whole-brain irradiation at a single-fraction of 20 Gy can induce radiological brain injury.

We quantified the severity of irradiation-associated cerebral edema by using tissue W/D ratio, which is one of the most reliable and intuitive approaches (41). According to the results, the progression of cerebral edema was inhibited after applying anlotinib. Furthermore, a positive correlation between the degree of cerebral edema and the expression of VEGF was observed. VEGF has been found to be a proangiogenic factor, however in the development of RBI, which confirmed as a crucial factor leading to abnormal angiogenesis with high permeability and breakdown of BBB $(42,43)$. Consequently, pathological levels of VEGF inevitably result in vasogenic cerebral edema (44), which was consistent with our data in the anlotinib treated groups. Also, Ma et al. (45) showed that thrombosis could be observed from 3 to 7 days after irradiation, while thrombus recanalization is first achieved at 14 days. In combination with the histological results, they believed that the sharp increase in BWC at 14 days after irradiation not only results from the over-expression of VEGF, but also with thrombus recanalization.

Using a rat model of post-irradiation CNS damage, Nordal et al. (11) demonstrated the temporal-spatial relationship between activated astrocytes (identified by GFAP expression), the expression level of HIF-1 $\alpha$, and its downstream target VEGF. They showed that cells producing both HIF- $1 \alpha$ and VEGF were identified as astrocytes, and the initial time points and expression pattern over time are considered highly coincident.
Furthermore, Nonoguchi et al. (5) argued that VEGFpositive astrocytes concentrated in hypoxic areas might be oneoftheprimecausesofirradiation-associatedcerebralede maandadverse effects after irradiation. Chávez et al. (46) constructed a rat model of chronic hypoxia, and showed that activated astrocytes exhibited HIF-1 $\alpha$, along with the induction of VEGF. Taken together, these studies focused our attention on VEGF and its upstream protein signaling in response to irradiation.

Our results exhibited a parallel relationship between the expression of GFAP and HIF- $1 \alpha$, with obvious downregulation after treatment with anlotinib in a significantly dose-dependent manner. The expression value presented a single peak pattern, appearing at 7 days after irradiation. However, the expression of VEGF was consistent with both GFAP and HIF-1 $\alpha$ only in the IR group. In contrast, the expression of VEGF remained elevated up to 14 days after anlotinib treatment. The downregulation of p-VEGFR2 was also in contrast with the upregulation of VEGF in the anlotinib treated groups. So, we contend that anlotinib effectively alleviated postirradiation injury by inhibiting the GFAP/HIF-1 $\alpha /$ VEGF/ VEGFR2 pathway. As stated previously, by upregulating the permeability of microvasculature the pathological level of VEGF induces cerebral edema, simultaneously causing a microcirculatory obstruction as well as hypoxia. This leads to further over-activation of the HIF-1 $\alpha / \mathrm{VEGF} /$ VEGFR2 signaling pathway, which could generate a vicious cycle between edema and hypoxia. Likewise, it has been shown that an activated HIF-1 $\alpha / \mathrm{VEGF/VEGFR2}$ signaling pathway results in hypoxia and pathological highpermeability angiogenesis of malignant tumours $(47,48)$. Given that HIF- $1 \alpha$ contributes to acquire resistance against anti-VEGF therapy, the use of an anti-VEGFR antibody presents as a potential treatment strategy for several tumours (49). Anlotinib, as a small molecule inhibitor of multiple receptor tyrosine kinases, can inhibit the VEGF/ VEGFR2 pathway, resulting in normalization of the tumour vasculature and improving internal oxygen supply. Thus we assert that, in the RBI model, downregulation of HIF- $1 \alpha$ in both the AL and AH groups might benefit from the effectiveness of anlotinib in improving internal oxygen supply. We speculate that the reduction of activated astrocytes may also participate in downregulating HIF$1 \alpha$, resulting from the decreased oxygen consumption. However, the exact mechanism in the downregulation of GFAP is not evident from the previous literature or our study, and further research is required. 
According to our data, anlotinib undoubtedly exerts its role as an inhibitor of VEGF-stimulated phosphorylation of VEGFR2 in a concentration-dependent way. Hence, we contend that this might responsible for the negative feedback enhancement of VEGF secretion. Although the expression of the VEGF protein was stimulated with anlotinib treatment in both the $\mathrm{AL}$ and $\mathrm{AH}$ groups, neither of them remained higher compared to the IR group. However, in this study, only acute clinical manifestations have been investigated whether the expression level of VEGF will increase sharply even higher than the IR group is not entirely clear. Anlotinib has been used in clinical practice for only a short time, and its application is still limited. In our study, anti-VEGFR therapy obtained therapeutic benefits in the mouse RBI model, and is worthy of more extensive investigation and broader exploration of the deeper mechanisms.

\section{Conclusions}

Whole-brain irradiation at a single-fraction of 20 Gy induced severe acute brain impairment in the mouse model, causing over-activation of astrocytes, hypoxia, demyelination, and irradiation-associated cerebral edema, which lasted for up to 14 days. However, treatment with anlotinib significantly mitigated the adverse effects of acute RBI in a dose-dependent manner by downregulating the activation of astrocytes, improving brain hypoxia, and alleviating cerebral edema. Although, anlotinib failed to inhibit the development of demyelination.

\section{Acknowledgments}

Funding: None.

\section{Footnote}

Reporting Checklist: The authors have completed the ARRIVE reporting checklist. Available at http://dx.doi. org/10.21037/apm-20-2284

Data Sharing Statement: Available at http://dx.doi. org/10.21037/apm-20-2284

Conflicts of Interest: All authors have completed the ICMJE uniform disclosure form (available at http://dx.doi. org/10.21037/apm-20-2284). The authors have no conflicts of interest to declare.
Ethical Statement: The authors are accountable for all aspects of the work in ensuring that questions related to the accuracy or integrity of any part of the work are appropriately investigated and resolved. Experiments were performed under a project license (No. 20191101-11) granted by Ethics Committee of Binzhou Medical University, in compliance with the National Research Council Guide for the Care and Use of Laboratory Animals.

Open Access Statement: This is an Open Access article distributed in accordance with the Creative Commons Attribution-NonCommercial-NoDerivs 4.0 International License (CC BY-NC-ND 4.0), which permits the noncommercial replication and distribution of the article with the strict proviso that no changes or edits are made and the original work is properly cited (including links to both the formal publication through the relevant DOI and the license). See: https://creativecommons.org/licenses/by-nc-nd/4.0/.

\section{References}

1. Balentova S, Adamkov M. Molecular, cellular and functional effects of radiation-induced brain injury: A review. Int J Mol Sci 2015;16:27796-815.

2. Yang L, Yang J, Li G, et al. Pathophysiological responses in rat and mouse models of radiation-induced brain injury. Mol Neurobiol 2017;54:1022-32.

3. Coderre JA, Morris GM, Micca PL, et al. Late effects of radiation on the central nervous system: role of vascular endothelial damage and glial stem cell survival. Radiat Res 2006; 166:495-503.

4. Liu Y, Xiao S, Liu J, et al. An experimental study of acute radiation-induced cognitive dysfunction in a young rat model. AJNR Am J Neuroradiol 2010;31:383-7.

5. Nonoguchi N, Miyatake SI, Fukumoto M, et al. The distribution of vascular endothelial growth factorproducing cells in clinical radiation necrosis of the brain: pathological consideration of their potential roles. J Neurooncol 2011;105:423-31.

6. Good RR, Herndon R, Maniscalco W, et al. Myelin basic protein $(\mathrm{mbp})$ as an early predictor of delayed radiation myelopathy in the rabbit model. Int Radiat Oncol 1984;10:102-3.

7. Calvo W, Hopewell JW, Reinhold HS, et al. Time- and dose-related changes in the white matter of the rat brain after single doses of x rays. Brit J Radiol 1988;61:1043-52.

8. Deng Z, Huang $\mathrm{H}, \mathrm{Wu} \mathrm{X}$, et al. Distinct expression of various angiogenesis factors in mice brain after whole-brain 
irradiation by x-ray. Neurochem Res 2017;42:625-33.

9. Serduc R, Yohan VDL, Francony G, et al. Characterization and quantification of cerebral edema induced by synchrotron $\mathrm{x}$-ray microbeam radiation therapy. Phys Med Biol 2008;53:1153-66.

10. Kobierska A, Karnicka-Młodkowska H, Solska E. Radiotherapy of neoplasms of the central nervous system. Neurol Neurochir Pol 1983;17:85.

11. Nordal RA, Nagy A, Pintilie M, et al. Hypoxia and hypoxia-inducible factor-1 target genes in central nervous system radiation injury: A role for vascular endothelial growth factor. Clin Cancer Res 2004;10:3342-53.

12. Kyrkanides S, Olschowka JA, Williams JP, et al. TNF alpha and IL-1beta mediate intercellular adhesion molecule-1 induction via microglia-astrocyte interaction in CNS radiation injury. J Neuroimmunol 1999;95:95-106.

13. Glass CK, Saijo K, Winner B, et al. Mechanisms underlying inflammation in neurodegeneration. Cell 2010;140:918-34.

14. Ridet JL, Malhotra SK, Privat A, et al. Reactive astrocytes: cellular and molecular cues to biological function. Trends Neurosci 1997;20:570-7.

15. Wang GL, Semenza GL. Purification and characterization of hypoxia-inducible factor 1 . J Biol Chem 1995;270:1230-7.

16. Huang LE, Gu J, Schau M, et al. Regulation of hypoxiainducible factor 1alpha is mediated by an O2-dependent degradation domain via the ubiquitin-proteasome pathway. Proc Natl Acad Sci USA 1998;95:7987-92.

17. Ferrara N, Gerber HP, LeCouter J. The biology of VEGF and its receptors. Nat Med 2003;9:669-76.

18. Shibuya M. Vascular endothelial growth factor and its receptor system: physiological functions in angiogenesis and pathological roles in various diseases. J Biochem 2013;153:13-9.

19. Takahashi S. Vascular endothelial growth factor (VEGF), VEGF receptors and their inhibitors for antiangiogenic tumor therapy. Biol Pharm Bull 2011;34:1785-8.

20. Rini BI, Small EJ. Biology and clinical development of vascular endothelial growth factor-targeted therapy in renal cell carcinoma. J Clin Oncol 2005;23:1028-43.

21. Lee SW, Kim WJ, Jun HO, et al. Angiopoietin-1 reduces vascular endothelial growth factor-induced brain endothelial permeability via upregulation of ZO-2. Int J Mol Med 2009;23:279-84.

22. Gonzalez J, Kumar A, Conrad CA, et al. Effect of bevacizumab on radiation necrosis of the brain.Int J Radiat Oncol Biol Phys 2007;67:323-6.
23. Levin VA, Bidaut L, Hou P, et al. Randomized doubleblind placebo-controlled trial of bevacizumab therapy for radiation necrosis of the central nervous system. Int J Radiat Oncol Biol Phys 2011;79:1487-95.

24. Tye K, Engelhard HH, Slavin KV, et al. An analysis of radiation necrosis of the central nervous system treated with bevacizumab. J Neurooncol 2014;117:321-7.

25. Perez-Torres CJ, Yuan L, Schmidt RE, et al. Specificity of vascular endothelial growth factor treatment for radiation necrosis.Radiother Oncol 2015;117:382-5.

26. Xie C, Wan X, Quan H, et al. Preclinical characterization of anlotinib, a highly potent and selective vascular endothelial growth factor receptor-2 inhibitor. Cancer Sci 2018;109:1207-19.

27. Kerbel RS. Antiangiogenic therapy: A universal chemosensitization strategy for cancer? Science 2006;312:1171-5.

28. Jain RK. Normalization of tumor vasculature: an emerging concept in antiangiogenic therapy. Science 2005;307:58-62.

29. Han B, Li K, Zhao Y, et al. Anlotinib as a third-line therapy in patients with refractory advanced non-smallcell lung cancer: a multicentre, randomised phase II trial (alter0302). Brit J Cancer 2018;118:654-61.

30. Yang S, Zhang Z, Wang Q. Emerging therapies for small cell lung cancer. J Hematol Oncol 2019;12:47.

31. Zhu Y, Ling Y, Zhong J, et al. Magnetic resonance imaging of radiation-induced brain injury using targeted microparticles of ironoxide. Acta Radiol 2012;53:812-9.

32. Wong CS, Der Kogel AJV. Mechanisms of radiation injury to the central nervous system: implications for neuroprotection. Mol Interv 2004;4:273-84.

33. Li YQ, Guo YP, Jay V, et al. Time course of radiationinduced apoptosis in the adult rat spinal cord. Radiother Oncol 1996;39:35-42.

34. Roman DD, Sperduto PW. Neuropsychological effects of cranial radiation: current knowledge and future directions. Int J Radiat Oncol Biol Phys 1995;31:983-98.

35. Welzel G, Fleckenstein K, Mai SK, et al. Acute neurocognitive impairment during cranial radiation therapy in patients with intracranial tumors. Strahlenther Onkol 2008;184:647-54.

36. Donato R. Intracellular and extracellular roles of s100 proteins. Microsc Res Tech 2003;60:540-51.

37. Gonçalves CA, Leite MC, Nardin P. Biological and methodological features of the measurement of s100b, a putative marker of brain injury. Clin Biochem 2008;41:755-63.

38. González-Quevedo A, Gonzalez-Garcia S, Concepción 
$\mathrm{OF}$, et al. Increased serum s-100b and neuron specific enolase-potential markers of early nervous system involvement in essential hypertension. Clin Biochem 2011;44:154-9.

39. Pham N, Fazio V, Cucullo L, et al. Extracranial sources of S100B do not affect serum levels. PLoS One 2010;5:e12691.

40. Lippi G, Aloe R, Numeroso F, et al. The significance of protein S-100B testing in cardiac arrest patients. Clin Biochem 2011;44:567-75.

41. Benlier E, Eskiocak S, Puyan FO, et al. Fucoidin, a neutrophil rolling inhibitor, reduces damage in a rat electrical burn injury model. Burns 2011;37:1216-21.

42. Lee WH, Cho HJ, Sonntag WE, et al. Radiation attenuates physiological angiogenesis by differential expression of VEGF, ANG-1, TIE-2 and ANG-2 in rat brain. Radiat Res 2011;176:753-60.

43. Owen MR, Alarcón T, Maini PK, et al. Angiogenesis and vascular remodelling in normal and cancerous tissues. $\mathrm{J}$ Math Biol 2009;58:689-721.

44. Jin X, Liang B, Chen Z, et al. The dynamic changes of capillary permeability and upregulation of VEGF in rats following radiation-induced brain injury. Microcirculation 2014;21:171-7.

45. Ma C, Zhou J, Xu X, et al. The construction of a radiation-induced brain injury model and preliminary study on the effect of human recombinant endostatin in treating radiation-induced brain injury. Med Sci Monit 2019;25:9392-401.

46.Chávez JC, Agani F, Pichiule P, et al. Expression of hypoxiainducible factor- $1 \alpha$ in the brain of rats during chronic hypoxia. J Appl Physiol 2000;89:1937-42.

47. Jain RK, Duda DG, Willett CG, et al. Biomarkers of response and resistance to antiangiogenic therapy. Nat Rev Clin Oncol 2009;6:327-38.

48. Buysschaert I, Schmidt T, Roncal C, et al. Genetics, epigenetics and pharmaco-(epi)genomics in angiogenesis. J Cell Mol Med 2008;12:2533-51.

49. Carmeliet P, Jain RK. Molecular mechanisms and clinical applications of angiogenesis. Nature 2011;473:298-307.

(English Language Editor: A. Kassem)
Cite this article as: Gao XH, Zheng J, Ma L, Ma LB, Zhai YJ, Yang FF, Wang SJ, Fan QS, Wen J, Wang HL, Wu XH, Chen SS, Liu CM. Mitigation of acute radiation-induced brain injury in a mouse model using anlotinib. Ann Palliat Med 2021;10(1):312322. doi: 10.21037/apm-20-2284 